\title{
BAFF polymorphisms and serum levels of BAFF in Tunisian systemic lupus erythematosus patients
}

\author{
Nacira Laamiri ${ }^{1}$ Imen Sfar ${ }^{1}$, Tarak Dhaouadi', Lamia Ben Hassine², Salwa Jendoubi-Ayed ${ }^{1}$, Awatef Chiha' \\ Thouraya Ben Romdhane1, Mouna Makhlouf', Taïeb Ben Abdallah', Narjess Khalfallah², Khaled Ayed', \\ Yousr Gorgi ${ }^{1 *}$
}

From 7th European Workshop on Immune-Mediated Inflammatory Diseases

Noordwijk aan Zee, the Netherlands. 28-30 November 2012

\section{Introduction}

Although different authors suggest that the B-lymphocyte activating factor (BAFF) may be involved in the selective loss of B-cell tolerance in human systemic lupus erythematosus (SLE), the mechanisms responsible for the deregulation of this molecule in SLE remain unclear [1-3].

\begin{abstract}
Aims
To investigate any associations between regulatory genetic polymorphisms of BAFF gene, disease susceptibility and serum BAFF (s-BAFF) levels in Tunisian systemic lupus (SLE) patients.
\end{abstract}

\section{Methods}

The case-control study included 124 SLE patients and 152 healthy controls. Three single nucleotide polymorphisms (SNPs) $(-2841 \mathrm{~T}>\mathrm{C},-2701 \mathrm{~A}>\mathrm{T}$ and $-871 \mathrm{C}>\mathrm{T})$ in the ${ }^{\prime}$ regulatory region of the BAFF gene were explored by PCR-RFLP [4]. s-BAFF levels were measured by ELISA (R\&D Systems).

\section{Results}

s-BAFF levels were elevated in SLE patients $(1717,08 \mathrm{pg} / \mathrm{ml})$ and in anti-dsDNA positive antibodies patients $(1948,28$ $\mathrm{pg} / \mathrm{ml})$ compared to both controls $\left(665,82 \mathrm{pg} / \mathrm{ml}, \mathrm{p}<10^{-3}\right)$ and patients without anti-dsDNA antibodies (1281,51 $\mathrm{pg} / \mathrm{ml}, \mathrm{p}: 0,007)$. In contrast, no correlation was found between global disease activity registered in SLEDAI and s-BAFF levels (p: 0.7). Furthermore, no association was found between BAFF genotypes and susceptibility to SLE. Single allele, genotype and haplotype association analyses

${ }^{1}$ Research Laboratory of Renal Transplantation and Immunopathology (LR03SP01), University Tunis El Manar, Charles Nicolle Hospital, Tunisia Full list of author information is available at the end of the article showed no significant association with s-BAFF values, clinical features or SLEDAI score in SLE.

\section{Conclusions}

Polymorphisms in the regulatory region of the BAFF gene do contribute neither to increased s-BAFF levels nor to the susceptibility to SLE in Tunisian patients. Increased s-BAFF levels in anti-dsDNA positive antibodies SLE patients suggest the central role of this molecule in the inflammatory process involving in autoantibodies production.

\section{Author details}

${ }^{1}$ Research Laboratory of Renal Transplantation and Immunopathology (LRO3SP01), University Tunis El Manar, Charles Nicolle Hospital, Tunisia. ${ }^{2}$ Dept. of Medicine, Charles Nicolle Hospital, Tunis, Tunisia.

Published: 28 November 2012

\section{References}

1. Becker-Merok A, Nikolaisen C, Nossent HC: B-lymphocyte activating factor in systemic lupus erythematosus and rheumatoid arthritis in relation to autoantibody levels, disease measures and time. Lupus 2006, 15:570-6.

2. Zhang J, Roscheke V, Baker KP: A role of B lymphocyte stimulator in systemic lupus erythematosus. J Immunol 2001, 166:6-10.

3. Eilertsen G, Van Ghelue M, Strand H, Nossent J: Increased levels of BAFF in patients with systemic lupus erythematosus are associated with acutephase reactants, independent of BAFF genetics: a case-control study. Rheumatology 2011, 50:2197-2205.

4. Nossent JC, Lester S, Zahra D: Polymorphism in the 5'regulatory region of the B-lymphocyte activating factor gene is associated with the RO/La autoantibody response and serum BAFF levels in primary Sjogren's syndrome. Rheumatology 2008, 47:1311-6.

doi:10.1186/1479-5876-10-S3-P35

Cite this article as: Laamiri et al.: BAFF polymorphisms and serum levels of BAFF in Tunisian systemic lupus erythematosus patients. Journal of Translational Medicine 2012 10(Suppl 3):P35. 